\title{
Appraisal of moisture problem of inheritance building envelope assemblies via visible and infrared thermography methods
}

\begin{abstract}
In order to gauge the moisture performance of walls and roofs there is a need to investigate the paths of moisture penetrating into the wall assembly, how long and where the moisture stays, and whether it causes temporary reduction of performance or permanent damage. The non-contact safe nature and usefulness in temperature measurement of infrared thermography have made it a popular instrument for building diagnostics. Hence, this paper depicts a documentation process which makes use of both visible and infrared thermal images to identify moisture anomalies in heritage building envelope assemblies. In sequence to achieve the purpose, visible and infrared thermal images are recorded for comparison and further analysis. It can be concluded that infrared thermal imaging camera is useful for identification of moisture problems in building façade, whereas combination of both visible and infrared thermal imaging methods produces a more advanced, accurate and effective approach for building diagnostics stress.
\end{abstract}

